\title{
Illustrium Imagines (Roma, 1517) de Andrea Fulvio, fuente de la decoración escultórica de la fachada del palacio de Riquelme de Jerez de la Frontera (1542-1543)
}

\author{
Juan Antonio Moreno Arana \\ Universidad de Sevilla \\ morenoarana@gmail.com
}

La influencia de los llamados Libros de medallas en la configuración formal y temática de los distintos programas iconográficos (como pone de manifiesto el valioso testimonio de Agustín, 1587: 87-88), muy especialmente dentro de la producción arquitectónica del Renacimiento, es un terreno de investigación con un todavía corto recorrido historiográfico, pero que está aportando interesantes perspectivas sobre los cauces de difusión de la cultura humanística en España1. En el ámbito andaluz, la utilización de la medalla dentro de la arquitectura civil renacentista tiene un notorio ejemplo en Jerez de la Frontera con la fachada del llamado palacio de Riquelme. El 11 de septiembre de 1542 el veinticuatro Fernando Riquelme ${ }^{2}$ contrata la obra de la fachada de su casa de la plaza del Mercado con el equipo encabezado por el «albañy» vecino de la ciudad Fernando Álvares ${ }^{3}$. Este frontispicio se proyectará siguiendo los cánones humanísticos de evocación e identificación con el mundo clásico [1].

En su familia, Riquel contaba con personas con una formación humanística que pudieron haberle asesorado, tal sería el caso del canónigo Hernando Riquel (Sánchez Saus, 1996: 153). Aunque nada sabemos de la formación intelectual de Riquel -su firma indica, al menos, soltura con la escritura-, su intervención directa en la elaboración del repertorio simbólico-decorativo de la fachada pone de manifiesto una cierta familiaridad con unas expresiones culturales utilizadas, en este caso, como signos del Poder. Esta obra sería una operación consciente de índole política encaminada a consolidar su estatus social preeminente y otorgar reputación al linaje Riquel, fin último al que consagra su estrategia vital ${ }^{4}$. La fachada construye, así, un discurso escenográfico, a modo de arco de Triunfo, en el que la ventana proyectada en ella tenía un papel central en esa representación de la idea hu-

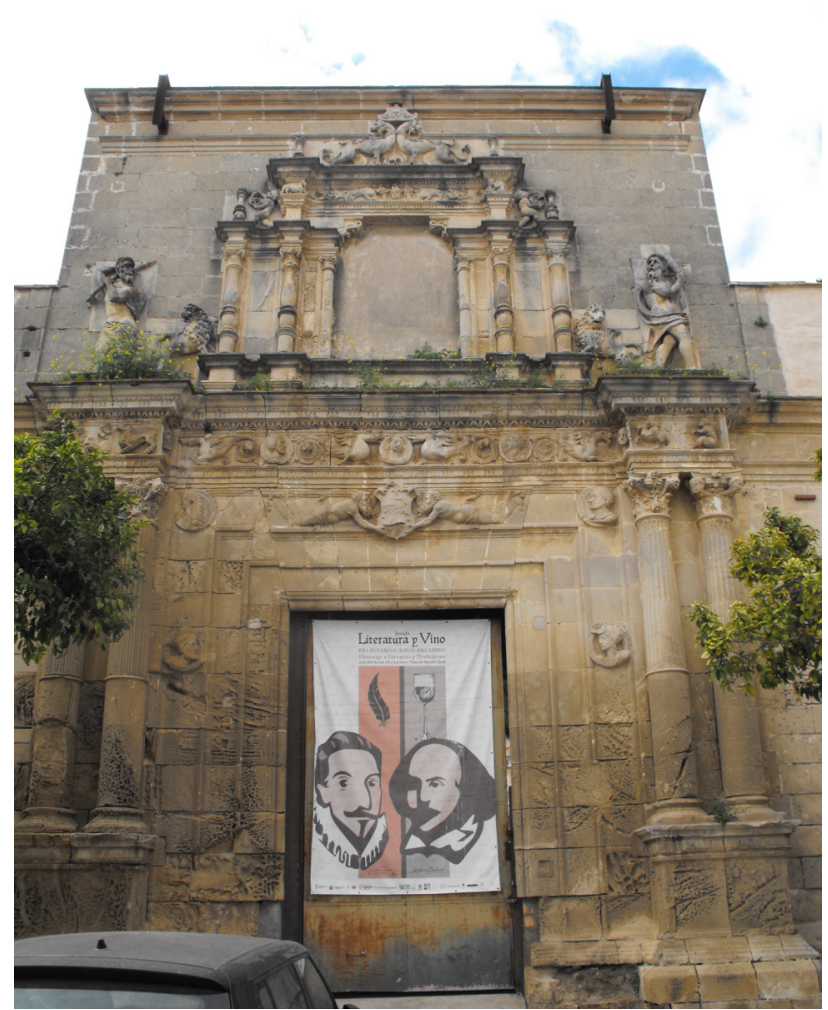

1. Estado actual del Palacio Riquelme, Jerez de la Frontera. Foto: Jesús Moreno

manista de la Fama como producto de las acciones virtuosas $^{5}$. Unas acciones virtuosas o heroicas a la que los Riquel pretenden enlazarse a través de una genealogía mítica que las medallas personifican metafóricamente. 


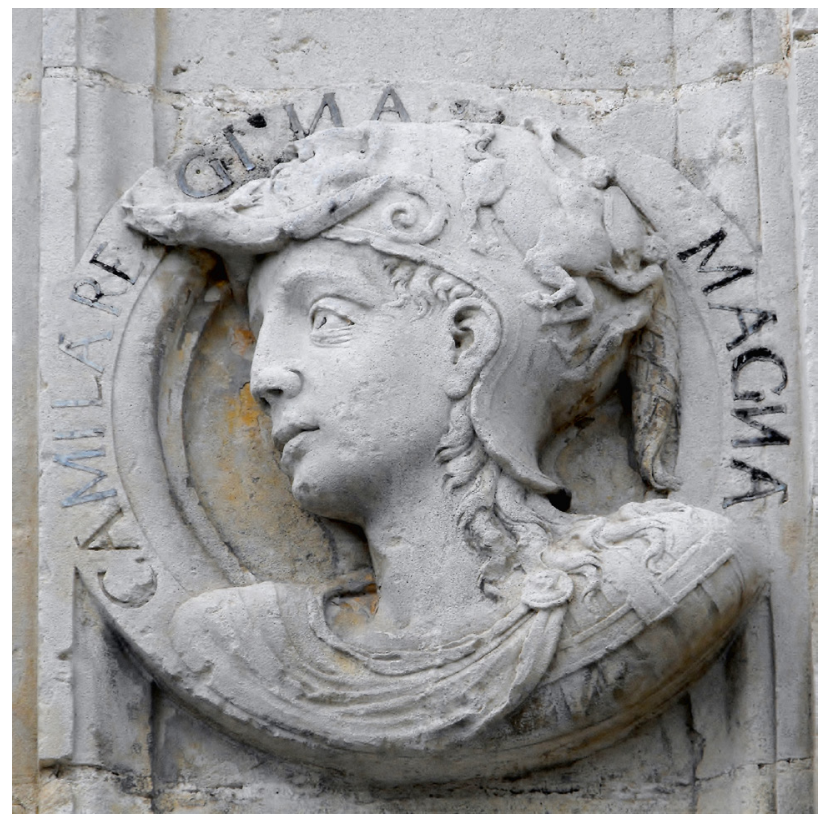

2. Medallón de la reina Camila Magna, Palacio Riquelme, Jerez de la Frontera. Foto: Jesús Moreno

En efecto, y centrándonos en al asunto que nos ocupa, entre los detalles concertados entre Riquel y Álvares estaba "que en los rincones del dentel haya dos medallas e debaxo destas dichas medallas aveys de fases en cada parte dos o tres». Esta condición, como otras, fue modificada en la ejecución final de la fachada. Así, únicamente se realizan cuatro medallas flanqueando el vano adintelado que da forma a la puerta principal de la casa ${ }^{6}$. Estos medallones se distribuyen en parejas, dispuestos uno encima del otro, en cada una de las jambas de la puerta. A la izquierda se coloca la medalla del emperador Constantino Magno y debajo de ella la de Nabucodonosor, rey de Babilonia. En la jamba derecha, arriba, el medallón con el retrato doble de Rómulo y Remo y bajo este el de Camila Magna, mítica reina de los Volscos y, como los hijos de la vestal Rea Silvia, criada entre bestias. Todos los medallones cuentan con un titulus identificando al personaje, escrito en letras mayúsculas y en latín, dentro de la moldura del tondo. El retrato, realizado en relieve, rebasa los límites de la orla o moldura de la medalla, quedando esta como fondo. Los modelos formales más cercanos para esta tipología de tondo estarían en la galería de personajes ilustres realizados para el zócalo de la iglesia de San Marcos de León, sede de la orden de Santiago (década de 1530).
Aguayo Cobo (2003: 12) advirtió que el retrato del medallón de Constantino Magno remite a uno de los incluidos en el basamento de la fachada de la Cartuja de Pavía (décadas de 1480-1490), cuya talla está atribuida a Giovanni Antonio Amadeo y su equipo, y que pasa por ser el repertorio de medallas más extenso creado para un edificio en Italia. Consta de sesenta y un medallones con los retratos de personajes del Antiguo Testamento, la mitología y la historia antigua, junto a algunos tondos alegóricos. Un número importante de ellos se inspira en medallas francesas del siglo XV (Burnet-Schofield, 1997: 5-28). Posteriormente, Corzo Sánchez (2007) abundará en esta procedencia iconográfica, ampliándola a los medallones de Rómulo y Remo y Nabucodonosor, evidenciándose la gran precisión con que son reproducidos por el autor de los clípeos de Riquelme. La presencia en Jerez de estas copias de los retratos de la Cartuja de Pavía no carece de interés, ya que incluso en el propio entorno lombardo apenas se cuenta con unas reproducciones tan fieles como éstas (Burnet-Schofield, 1997: 10).

Sin embargo, para el medallón de Camila Magna no se había hallado fuente iconográfica alguna [2]. En la serie de Pavía no consta ningún retrato femenino (Burnet-Schofield, 1997: 5). El modelo hay que buscarlo en la obra sobre personajes ilustres de la antigüedad publicada en Roma en 1517 por Andrea Fulvio. El Illustrium Imagines es uno de los primeros Libros de Medallas o de Icones que emplea y difunde el tipo formal procedente de la numismática antigua, y que rescata el simbolismo clásico del retrato como ejemplo de Virtudes o como memoria de antepasados ilustres (Bury, 2008: 157). El entallador del medallón jerezano se inspira, en concreto, en el retrato que acompaña el elogio de Alejandro Magno [3]. En el retrato estampado por Fulvio, el rey aparece mirando hacia la derecha, ataviado de guerrero y con un yelmo que luce una llamativa máscara frontal. En el lado visible del casco se bosqueja una escena de la lucha entre Centauros y Lapitas, siguiendo a la letra los textos literarios clásicos que describen las armas de los héroes guarnecidas con este tipo de escena; por ejemplo, la escena de Centauros y Lapitas aparecía en el escudo de Heracles (Hesíodo, 2013: 139). El yelmo se copia al detalle en el medallón de Riquelme. Con la identificación de la fuente iconográfica de este tondo se puede descartar el discurso iconológico sugerido (Aguayo Cobo, 2003: 23) a partir de la citada escena representada en el casco de Camila Magna. 
La falta de una fuente iconográfica para el retrato de Camila Magna ${ }^{7}$ obligó al autor de estas labores escultóricas, que parece especializado en este tipo de obras - se le puede atribuir con seguridad su trabajo en los medallones contemporáneos a los de Riquelme del patio del palacio del comendador santiaguista y veinticuatro Pedro de Benavente también en Jerez; muy visibles son los lazos estilísticos entre el medallón de Camila y el de la reina Dido de Benavente-, a echar mano del retrato andrógino del rey macedonio del Illustrium Imagines. Esta adaptación indicaría que la elección de Camila Magna para formar parte de esta pequeña galería de personajes ilustres estuvo determinada por un discurso simbólico prefijado. No obstante, no debe ser descartado otro hecho. Sin entrar en conflicto con el mensaje general que Riquel quería dar con estos medallones, quizás estos retratos concretos hayan sido preferidos por la vistosidad y lucimiento que el artista podría alcanzar con ellos. Y, en efecto, así lo parecen demostrar los cambios que introduce en orden formal, de volumen y de aparato ornamental, alejándose de la simple reproducción de patrones numismáticos, con respecto a los tondos de Pavía.

Por todo ello, nos inclinamos a pensar que la selección de estos retratos se hizo tomándolos del repertorio iconográfico que el propio artista presentaba a sus clientes. Una colección en la que estarían incluidos los modelos procedentes del Illustrium Imagines, como, también, dibujos o

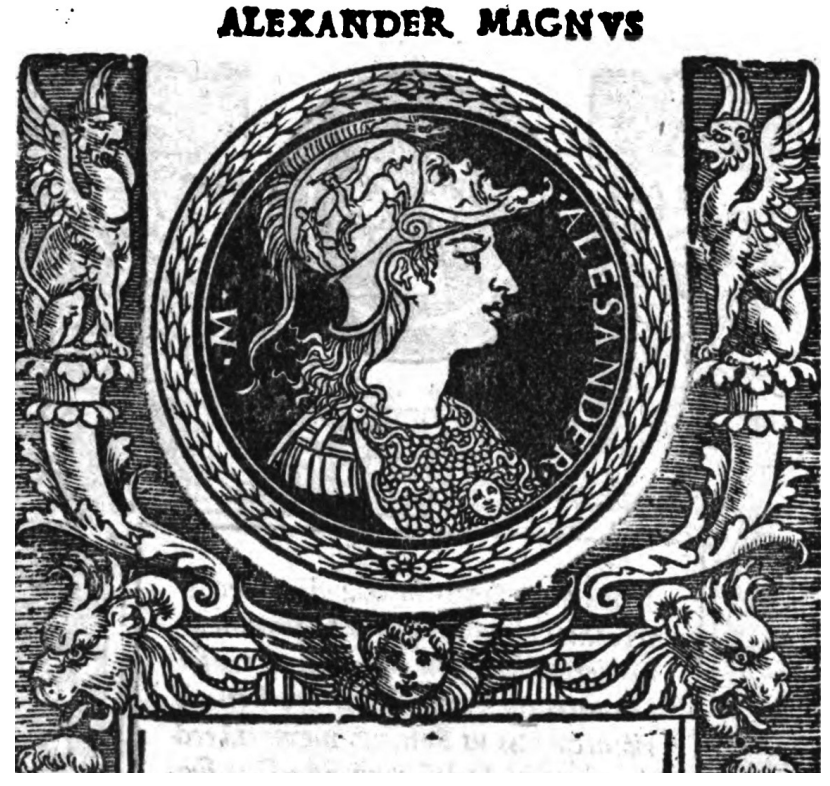

3. Alejandro Magno según Illustrium Imagines (Roma, 1517) de A. Fulvio

estampas que reprodujeran, entre otros, los medallones de Pavía o las fuentes de estos ${ }^{8}$. Este es un hecho que creemos de gran interés para desvelar el bagaje cultural y laboral que traía consigo el artista que produjo estas singulares -y amenazadas- piezas del Renacimiento español.

\section{Notas}

1 Incluimos en esta definición los llamados lcones o libros de retratos de personajes ilustres. Sobre el afán humanista por recuperar los valores del mundo clásico a través de la numismática: López Torrijos (1993); Blázquez Cerrato (2013); Zafra Molina (2014); Blázquez Cerrato (2016).

2 El clan nobiliario Riquel o Riquelme en Jerez es estudiado en: Sánchez Saus, 1996:151-157.

3 El palacio de Riquelme cuenta con una bibliografía amplia. Nos remitimos a los estudios más recientes: Guzmán Oliveros - Orellana González (2001); Aguayo Cobo (2003); Corzo Sánchez (2007); Romero Bejarano (2015). La fachada debía seguir en anchura y altura a la de la casa del escribano Francisco de Siles, pero no, como Corzo y Romero erróneamente han interpretado, seguir parte de su traza.

4 En 1560, Riquel y su mujer fundan un mayorazgo sobre la casa, junto a unas tierras y viñas, en cabeza de su hijo Bartolomé: Archivo de Protocolos Notariales de Jerez de la Frontera (APNJF), tomo 416 (oficio 1, año 1560), ff. 244r.-247r. En esta estrategia entraría la llamativa transformación del apellido familiar, quizás un intento de esconder o de prestigiar una genealogía de orígenes «oscuros». En su testamento, fechado en 1573, Fernando Riquel ya firma como Riquelme: APNJF, tomo 597 bis (oficio 1, año 1573), ff. 1287r.-1292r.

5 Sobre estos modelos visuales de representación social y política tan populares y difundidos en la época a través de la estampa, véase: Bury, $2008: 156-157$.

6 Otro cambio introducido a posteriori son los dos medallones enfrentados que presentan un hombre y una mujer que miran hacia un tondo central donde se retrata una figura femenina de aspecto juvenil, que a su vez mira hacia el tondo de la mujer. Se colocarán en el friso del entablamento que divide la fachada. Carecen de título, así como de vestimenta o atributos claros que los identifiquen. Tampoco tienen una correspondencia clara en los Libros de Medallas, salvo quizás en el caso del tondo de la mujer, cuyo peinado podría ser una interpretación del que lucen algunas damas romanas del catálogo de Andrea Fulvio. Todo ello, unido a la erosión que sufre la piedra, hace difícil proponer una identificación fiable. Aunque desde luego, su configuración en forma de medallas avalaría que sean retratos -quizás metafóricos-, y no representación de Vicios, como ha sido propuesto por Aguayo Cobo (Aguayo Cobo, 2003: 17). Con todo, creemos, siguiendo en parte la línea interpretativa de este último autor, que estos tres medallones pueden estar relacionados con la idea de Concordia marital, interpretando modelos procedentes de reversos de algunas medallas romanas y griegas. Quizás en este sentido pueda interpretarse el peinado de la mujer (¿representa cornucopias?). Es interesante recordar, en este sentido, que el mayorazgo, cuyo bien principal era la propia casa, lo fundan juntos 
Fernando Riquel y su mujer Inés Riquel. No era infrecuente la aparición de esta alegoría en decoraciones arquitectónicas; la encontramos, precisamente, en el basamento de la Cartuja de Pavía. Los modelos iconográficos de la Concordia procedentes de la numismática antigua los recoge: Agustín, 1587 : 44-45.

7 Una fuente iconográfica en: De plurimis claris sceletisque mulieribus opus prope diuinu novissime congestum (Ferrara, 1497) de Jacobus Bergomensis. En esta obra se estampa la escena clave de las vidas de las biografiadas. Son modelos estereotipados, lejos de una caracterización en forma de retrato.

8 En este sentido, es interesante indicar que el retrato de Nabucodonosor, tal y como es plasmado tanto en Pavía como en Riquelme, aunque sin las decoraciones que este último exhibe, se reproduce en el Promptuarii Iconum Insigniorum (Lyon, 1553) de Guillaume de Rouille. Esto evidenciaría que Rouille pudiera haberlo tomado del basamento de la Cartuja de Pavía. O, lo que es muy posible, que ambas obras tuvieran una fuente común en las medallas renacentistas de los siglos XV-XVI.

\section{Bibliografía}

AGUAYO COBO, Antonio (2003), «El palacio de Riquelme: interpretación iconológica», Revista de Historia de Jerez, n. 9, pp. 9-26.

AGUSTíN, Antonio (1587), Diálogos de medallas, inscripciones y otras antigüedades, Felipe Mey, Tarragona.

BLÁZQUEZ CERRATO, Cruces (2013), «Emblema Hispaniae: la percepción histórica de España a través de la Numismática en los textos humanísticos», en Castro Santamaría, Ana- García Nistal, Joaquín (coords.), en La impronta humanista (ss. XV-XVIII). Saberes, visiones e interpretaciones, Palermo, pp. 363-376.

— (2016), «Los Libros de medallas renacentistas como referentes sociales y artísticos», en Actas del XV Congreso Nacional de Numismática. Patrimonio numismático y museos, Museo Arqueológico Nacional, Madrid, pp. 1217-1230.

BURNET, Andrew-SCHOFIELD, Richard (1997), «The Medallions of de Basamento of de Certusa di Pavia. Sources and influence», Arte Lombarda, n. ${ }^{\circ} 120$, pp. 5-28.

BURY, Michael, (2008), «Los retratos en estampa en la Europa del Renacimiento», en El retrato en el Renacimiento, Museo del Prado, Madrid, pp. 147-164

CORZO SÁNCHEZ, Ramón (2007), «Las réplicas de los medallones de Giovanni Antonio Amadeo para la Cartuja de Pavía en la casa de Riquelme de Jerez de la Frontera», Boletín de Bellas Artes, n. ${ }^{\circ} 35$, pp. 245-29.

GUZMÁN OLIVEROS, Natividad y ORELLANA GONZÁLEZ, Cristóbal (2001), «El palacio renacentista de Riquelme (Jerez de la Frontera, 1542)», Revista de Historia de Jerez, n. ${ }^{\circ}$, 2001, pp. 49-75.

HESIODO (2013), Teogonía, Trabajos y días, Escudo, Certamen, Alianza Editorial, Madrid.

LÓPEZ TORRIJOS, Rosa (1993), «Las medallas y la visión del mundo clásico en el siglo XVI español», en La visión del mundo clásico en el arte español, VI Jornadas de Arte, Departamento «Diego Velázquez» del CSIC, Madrid, pp. 93-104.

ROMERO BEJARANO, Manuel (2015), «Sobre la construcción del Palacio Riquelme», Diario de Jerez, 8 y 15 de febrero.

SÁNCHEZ SAUS, Rafael (1996), Linajes medievales de Jerez de la Frontera, 2 t., Ed. Guadalquivir, Sevilla.

ZAFRA MOLINA, Rafael (2014), "Los icones de varones ilustres: ¿Un sub-género emblemático?», IMAGO. Revista de Emblemática y Cultura Visual, n. ${ }^{\circ}$, pp. 129-143. 